and then transported 350 miles by pipeline to supplement the supply of towns gas. This main, reaching as far as Manchester and Leeds, will operate at a pressure of $1,000 \mathrm{lb}$./in. ${ }^{2}$ to bring methane for enrichment purposes to some eight area Gas Boards.

New works have been built for the gasification of coal at high pressure by the well-known Lurgi process, at Westfield in Scotland, and at Coleshill in the West Midlands. The use of high pressure at 20 or more atmospheres results from the technical needs of the process, but it has the compensating advantage that distribution problems are considerably reduced.

In the growing trends of turning towards oil gasification for towns, gas manufacture light petroleum distillates, byproducts of the oil refinery, have come very much into the picture. Since the advantages of chemical reactivity by catalytic reaction are applicable in this practice quite a number of new and compact processes have been evolved to meet the gas industry's nceds. This progress has boen accompanied by an acceleration of the design of new and improved equipment for the utilization of gas for both domestic and industrial purposes. A further point arising from the more novel processes that are likely to come into use is that the calorific value of the gas to be supplied will be higher than is customary to-day.

Sir Henry considered most significant the situation that may arise as foreshadowed by the discovery of a large natural gas field at Groningen in the north of Holland. Minor deposits of natural gas have been known for many years to exist in Great Britain, thus at Whitby and at Cousland in Scotland. The tremendous size of the finds of gas in Holland, however, has stimulated interest in the North Sea. At a distant epoch in geological history ancient seas covered part of North Europe, the whole of the North Sea and part of Great Britain. Deposits in these seas containing organic matter of animal and vegetable origin were covered by further rocks including those now represented by Permian Sandstones. These in turn were covered by salt layers and shales, now found to be buried in Holland at a depth of $10,000 \mathrm{ft}$. Fortunately for the Dutch, the hydrocarbon gases produced have been trapped in a reservoir rock, probably a porous sandstone, beneath the impervious salt and shales. If, as is believed to be almost certain, the rocks under the North Sea are of similar pattern and character to those under Holland and East Yorkshire, the presence of gas off shore is probable, and in large quantities. The accepted methods of seismic exploration are being undertaken and if the results are promising drilling will be undertaken. The matter lies at present in the domain of conjecture, and the prospects are difficult to assess. Nevertheless, these possibilities and the actual developments in hand, together with a possible hardening of world prices of oil as the demand increases, may well accelerate the prospects of gaseous fuel utilization in Britain. An added advantage this fuel possesses is its favourable features from the aspect of its efficient use.

As to the prospects of coal utilization in this context, a change in world availability of hydrocarbon oils and gases may make more attractive the extraction of coal by automative mining methods. Having in mind also the growing development of nuclear energy, Sir Henry Jones envisaged as a possibility the hydrogenation of coal, using hydrogen produced with the aid of nuclear heat, becoming the basis of gas production. Indeed, in this respect the Gas Council is conducting important lines of research into the hydrogenation and gasification of coal.

In a technological age, whatever may be the means, the ultimate target of a national heat and power policy must be the distribution of energy either through a wire or a pipe. The last-named should inevitably be the domain of the gas industry, which from this encouraging record is definitely making substantial strides in the needed directions.

\section{R. J. SARJANT}

\title{
BRITISH CONTINENTAL SHELF PETROLEUM
}

$\mathrm{D}$ ESPITE allurements of the discovery in 1959 of the major natural gas field in the province of Groningen in Holland, also intensive geophysical search for favourable geological structures beneath the North Sea by international petroleum interests since then (Nature, 200, $123 ; 1963$, and 201,$670 ; 1964)$, oil and gas potentialities of rocks lying beneath that sea-bed, at least the British sector of its continental shelf, still remain an unknown quantity. It is in this particular context that the Government's recent plans for exploration and production of oil and gas in the North Sea region must be interpreted. The newly published Act (S.I. 1964 No. 708, Continental Shelf Petroleum: The Petroleum (Production) (Continental Shelf and Territorial Sea) Regulations 1964. Pp. 20. London: H.M.S.O., 1964. 1s.) ceme into operation on May 15. It is clearly framed in unusually cautious and restrained terms and rightly so. The Groningen gas field lies some 150 miles east of the 'first designated area' of the British part of the shelf. Geologically much can happen to the rocks, equally to their hydrocarbon contents (if any), in far less than that distance in such a variable stratigraphical environment as the North Sea basin is likely to disclose. Justification for this search is technically not in question, but at least this Act ensures that, whatever the outcome, Britain's interests are henceforward amply safeguarded.

The Minister of Power, Mr. Erroll, in the House of Commons on April 7, described five main factors which, under this Act, will govern award of licences to operators to continue or to initiate search for oil, ultimately to produce if commercial quantities are found. He is reported thus: "First, the need to encourage the most rapid and thorough exploration ard economical exploitation of petroleum resources on the continental shelf. Secondly, the requirement that the applicant for a licence shall be incorporated in the United Kingdom and the profits of the operations shall be taxable here. Thirdly, in cases where the applicant is a foreign-owned coneern, how far British oil companies receive equitable treatment in that country. Fourthly, we shall look at the programme of work of the applicant and also at the ability and resources to implement it. Fifthly, we shall look at the contribution the applicant has already made or is making towards the development of resources of our continental shelf and the development of our fuel economy generally". This statement, while discouraging ad hoc speculators, at least bestows Government blessing on and moral backing for those British and allied international oil concerns who have in the past sponsored and paid heavily for underwater search for favourable structural indications of oil and gas pools offshore of these Islands.

The regulations provide for exploration licences giving the right to search for oil in an area stretching from the Straits of Dover to the Shetland Islands, and approximately halfway across the North Sea, excludirg areas already subject to exclusive licences. Such licences will cost $£ 1,000$ per annum each. Production licences will cost $£ 10$ per square mile for the first six years, increasing after that annually by increments up to as much as $£ 120$ per square mile. Should oil production be established at any site, operators will pay royalties of 12.5 per cent of the value of oil or gas at well-head, this being roughly in line with procedure in other oil-bearing countries. Costs of annual sums incurred in exploration will be deductæble from royalties which, on the face of it, seems an extremely fair basis of contract, always providing of course that 
submarine oil or gas fields, or both, are ultimately proved of commercial value. It has to be borne in mind, however, that offshore drilling for oil is a hazardous and expensive business, even in known seaward extensions of proved continental oilfields; production costs are likewise liable to be heavier than on land-based operations.

Some realistic prohibitions are included in the Act to which licensees must give heed. For example, once a licence is granted, the project will not be allowed to lie fallow; the work programme will be officially checked both as to time and progress. Again, no operations may be carried out ". . . in such manner as to interfere unjustifiably with navigation or fishing in the waters of the exploration area or with the conservation of the living resources of the sea". It may be safely assumed that if this Act gives a fillip to the quest for oil in the North Sea region (the Government is obviously anxious that no time is lost), these prohibitions will be the least of the problems facing the oil companies concerned.

H. B. Milner

\title{
SPINY LOBSTER INDUSTRY IN SOUTHERN AFRICA
}

$\mathrm{U}$ NTIL recently, only the Republic of South Africa, South-west Africa, Mozambique and Tristan da Cunha were engaged in Southern Africa in commercial lobster fishing and marketing.

Lobster fishing is one of the oldest activities of the Republic of South Africa, with lobster canning in the country reportedly dating back as far as 1890. No one knows exactly when lobster fishing on a commercial scale was started in South-west Africa, but it developed in the years following the First World War. Not until the end of 1946 was Mozambique's first lobster fishing company organized to export frozen tails, ehiefly to the United States. This company operated for a few years but later went into liquidation. From 1956 until 1959 there was no lobster fishing in Mozambique, but a new company was organized for the purpose towards the end of 1959 , lobster tail exports from Mozambique being resumed in 1960. The Tristan da Cunha lobster industry dates from the establishment of a lobster company in 1949 with South African capital and techniques. Over the years it grew into a thriving enterprise until it was destroyed by the volcanic eruption of October 1961.

Southern Africa is undoubtedly the most important lobster fishing and marketing region of the African con- tinent. It produces about 70-80 per cent of the annual output of live lobsters in Africa; it absorbs more than 90 per cent of Africa's yearly live lobster consumption; and exports all the African canned lobster and lobster meal, and nearly 85 per cent of the African frozen lobster tails. It does not, however, export any live lobster, or fresh or frozen whole lobster.

In 1960, known lobster exports from Africa consisted of some 10 million lb. frozen tails, slightly more than $800,000 \mathrm{lb}$. canned lobster and approximately $2 \cdot 25$ million $\mathrm{lb}$. fresh or frozen whole lobster. South-west Africa is a traditional producer of lobster meal with an annual export-level of 1.5-2 million $\mathrm{lb}$. of lobster meal.

A recent survey by D. J. Soares-Rebelo provides information on the spiny lobster industry in Southern Africa (South African Journal of Science, 60, No. 3; March 1964). Lack of details on Tristan da Cunha's thriving lobster industry prior to the volcanic eruption of October 1961 is counterbalanced with first-hand information on Mozambique's incipient lobster industry, and with profuse notes on the lobster industry of the Republic of South Africa and of South-west Africa.

\section{EVIDENCE FOR CONTINUITY BETWEEN THE CENTRAL ELEMENTS OF THE TRIADS AND EXTRACELLULAR SPACE IN FROG SARTORIUS MUSCLE}

\author{
By Dr. H. E. HUXLEY, M.B.E., F.R.S. \\ Medical Research Council Laboratory of Molecular Biology, University Postgraduate Medical School, Cambridge
}

\begin{abstract}
A. V. HILL ${ }^{1,2}$ has shown that the whole cross-sectional area of a frog sartorius muscle fibre becomes fully activated at $0^{\circ} \mathrm{C}$ within $40 \mathrm{msec}$ of the depolarization of the external membrane, and that this leaves insufficient time for any activating substance to reach the inner portions of the fibre in appreciable quantities by diffusion from the fibre surface. Hill concluded that a process, not a substanee, must conduct the signal for contraction inwards.

Electron-microscope observations ${ }^{3-6}$ have revealed the presence of an extensive system of internal membranes in muscle fibres. This has been named the sarcoplasmic reticulum, and corresponds to the reticular apparatus of classical light microscopy ${ }^{7-10}$. Several investigators have suggested ${ }^{3-6,11,12}$ that the reticulum, or a part of it, may provide the requisite structural pathway for the internal conducting process. The reticulum forms a well-defined structural system, lying in between the myofibrils, but repeating along the length of the muscle in register with the sarcomere repeat. The system consists of two distinguishable types of membrane-bound enclosure which do not communicate directly with each other or with the main part of the muscle sarcoplasm. One part of this system has the form of narrow longitudinal sheets or channels of enclosed sarcoplasm, often only $200-300 \AA$ in
\end{abstract}

width, running alongside each fibril along most of its length, and forming an almost complete sheath around it, but being interrupted, in the case of frog sartorius muscle, at the level of the $Z$-lines (in some other types of muscle, for example, rabbit psoas, the interruptions are near the level of the $A-I$ boundaries). Opposite the $I$ bands, the narrow sheets and channels open out into a broader terminal region or vesicle about $1000 \AA$ or so in width, which also encircles the fibril.

The other part of the reticulum has the form of predominantly transversely oriented tubules (the $T$-system ${ }^{13}$ ) at the level of the $Z$-lines in frog sartorius muscle, which are possibly continuous for considerable distances across the fibre. The transverse system has been suggested as the component of the reticulum which actually conducts the stimulus inwards ${ }^{13}$.

Where the terminal regions of the longitudinal system of the reticulum come into contact with the transverse system, a characteristic structure called a triad ${ }^{6}$ is formed, consisting of a central channel (part of the $T$-system, and opposite the $Z$-lines in frog sartorius muscle) flanked on either side by the two closely apposed terminal vesicles, one from each of the two adjoining sarcomeres. The appearance of the overall structure is shown in Fig. 1, 